\title{
Influence of Temperature on Energetic and Rheological Characteristics of PLANTOHYD Bio Lubricants - a Study in the Laboratory
}

\author{
Krassimira Kardjilova \\ Department of Physics \\ Technical University \\ of Varna \\ Varna, Bulgaria \\ kardjilova@yahoo.com
}

\author{
Vlasta Vozarova \\ Department of Physics \\ Slovak University of Agriculture \\ of Nitra \\ Nitra, Slovak Republic \\ vlasta.vozarova@uniak.sk
}

\author{
Mihal Valah \\ Department of Physics \\ Slovak University of Agriculture \\ of Nitra \\ Nitra, Slovak Republic \\ michal.valach@uniag.sk
}

\begin{abstract}
This article presents the results of measuring the calorific value and the rheological characteristics of Plantohyd bio lubricants. Measurements were conducted under laboratory conditions with an IKA C5000 calorimeter and a DV-3P Anton Paar digital viscometer. Results are presented graphically. It is shown that the physical interpretation of energy values results and the dependence of rheological properties on temperature can be used to assess the quality of lubricants.
\end{abstract}

Keywords: Plantohyd; calorific value; rheological characteristics; quality of lubricants.

\section{INTRODUCTION}

Biofuels and bio lubricants are widely entering the market, especially the liquid fuel market. Biofuels and bio lubricants are compatible with existing engines and vehicles, but produced from organic material (waste agricultural products, sunflower, rapeseed oil, etc.). Therefore, they are far more environment-friendly, whereas they are capable of producing similar energy values with ordinary fuels

Plantohyd lubricants are products based on synthetic esters, providing an alternative to petroleum-based hydraulic oils (e.g. [1]).

The main advantages of these lubricants are:

- Excellent composting - 90\% for 14 days;

- Excellent resistance to aging and oxidation;

- Good viscosity-temperature dependence.

Plantohyd hydraulic lubricants are suitable for all mobile and stationary hydraulic equipment in vehicles and industry. Their use is recommended especially when there is a danger of leakage of hydraulic and lubricating oisl in soil, groundwater or surface water.

To maintain their production properties, they must be used independently and not in combination with petroleumbased oils. They can be applied in a wide temperature range from $-35{ }^{\circ} \mathrm{C}$ to $+90{ }^{\circ} \mathrm{C}$, covered by different Plantohyd types.

There is little information for the energetic values of different lubricants. Changing other characteristics of the lubricants depending on temperature, pressure during use and storage conditions has also met limited investigation.

Measurements were conducted in the scientific laboratory of the Department of Physics of the Slovak University of Agriculture in Nitra. We measured the specific heat of combustion of three Plantohyd samples and of the dependence of rheological characteristics-dynamic viscosity $\eta$, kinematic viscosity $v$, fluidity $\varphi$ and density $\rho$ on temperature $t$. Measurement methods of thermophysical properties and their theoretical principles can be found in [2-5]

\section{THEORETICAL BASE}

Basic physical processes that can be used to measure the influence of temperature on physical properties of lubricants are the hot wire method [2] and thermal analysis methods [6]. Among the most common methods of thermal analysis are the thermo gravimetric analysis, the differential thermal analysis and the calorimetric differential compensatory difference.

The main quantity studied in thermal analysis methods is the change in enthalpy $\Delta H[3,7]$.

\section{A. Specific enthalpy (calorific value of fuels)}

The amount of energy generated when a unit mass of fuel is burned completely is known as the calorific value of the fuel. Enthalpy is a measure of the energy content in a thermodynamic (TD) system. For each balance state of the TD system, specific enthalpy has a specific value. The value of enthalpy and its change depend on the initial and final state of the TD system, rather than the intermediate states [4]. Specific enthalpy is the enthalpy per unit mass $[h]=\frac{\mathrm{kJ}}{\mathrm{kg}}$.

The change of specific enthalpy determines the heat released from the system at a fixed process. The release during the combustion of fuel energy transfers the products of combustion, which leads to a change in its enthalpy.

Enthalpy of combustion is defined as the difference between the enthalpy of the products and the enthalpy of 
reagents when complete combustion occurs at a given temperature and pressure [4].

In the combustion, the calorimeter technique is adopted to determine the enthalpy of combustion products that result from the fuel unit.

Enthalpy-energy diagrams, with graphical interpolation for intermediate values, can be used to determine the enthalpy of combustion products at different temperatures, excess air in the construction of thermal balance and the related thermo calculations of combustion.

In many cases however, the enthalpy of combustion, which can be experimentally determined, is used for energetic analysis when the enthalpy formation data are not directly accessible

Fast and precise enough measurement of the specific enthalpy (calorific value of fuels) can be acquired with a C5000 calorimeter.

\section{B. Rheological characteristics}

Rheology is a branch of physics, which deals with the ways in which materials and fluids deform in response to applied forces or stress [8]. Newton formulated the law for an ideal fluid: shear stress between layers is proportional to the velocity gradient, $\partial u / \partial y$, in a direction perpendicular to the layers, in other words, the relative movement of layers.

$$
\tau=\eta \frac{\partial u}{\partial y}
$$

Here, the constant $\eta$ is the coefficient of viscosity (viscosity) or dynamic viscosity.

Many fluids, such as water, satisfy Newton's criterion and are known as Newtonian fluids. Non-Newtonian fluids exhibit a more complex relationship between shear stress and velocity gradient. In some cases, the ratio of inertial resistance is calculated using fluid density $\rho$. Kinematic viscosity is determined by:

$$
v=\frac{\eta}{\rho}
$$

Reciprocal value of viscosity determines the fluidity

$$
\varphi=\frac{1}{\eta}
$$

It is known that dynamic viscosity changes with temperature, which means that this impact will also occur in kinematic viscosity and fluidity.

Theoretical and experimental studies show that this dependence is exponentially or linearly decreasing for $\eta$ and $v$ and linearly or exponentially increasing for $\varphi[8,9]$.

The dependencies are determined by the kind of the substance and the manner of processing and storage. This means that many different fluids are required in order to investigate the dependency of rheological properties on temperature.

\section{MODEL AND METHOD OF MEASUREMENT}

Three samples of Plantohyd (15S, 46S and 40N) were examined.

Measurements were made under laboratory conditions in air temperature $t=21^{\circ} \mathrm{C}$, atmospheric pressure and normal humidity $\omega=56 \%$.

All calorie values are measured two times and all rheological three times. The presented results are average values.

\section{A. Measurement of energy values}

Measurements are performed with an IKA Calorimeter system C5000 control (C5040 CalWin) [3, 7]. The selected operating condition is adiabatic. Calibration of the apparatus is conducted before the measurement, in order to achieve a high degree of precision and accuracy

The masses of the samples are measured with a digital balance accurate to $0.0001 \mathrm{~g}$ and then the samples are placed in a calorimetric bomb in which the combustion process takes place, under certain conditions. The specific heat of combustion is calculated based on data obtained for the mass of the samples, the heat capacity of the calorimeter and the temperature rise of the water in the calorimeter.

\section{B. Measurement of rheological values}

Measurements are made with a DV-3P Anton Paar digital viscometer, which is a rotational viscometer [8]. It holds and operates on the principle of measuring the torsion force as a function of resistance, which has a model for the rotation of the cylinder or spindle immersed in the sample. Viscosity is calculated from the measured values. The combination of spindles (R2, R3) and speed allows an optimal choice for measuring viscosity.

Measurements of viscosity should be conducted in laminar flow, which requires a specific time (in our case 2 minutes). There should be no air bubbles in the model. It should have a uniform texture and should be free of mechanical impurities. The temperature must be constant throughout the volume of the sample. Only under these conditions, the measured value of viscosity can be considered correct. The density of the samples is measured using the pycnometric method and a calibrated pycnometer with a volume of $50 \mathrm{ml}$.

The dynamic viscosity of the three samples was measured at different temperatures. For the same temperature range, we measured the densities of the samples and calculated kinematic viscosity and fluidity.

\section{RESULTS}

The energetic values of the three Plantohyd samples are shown in Table I.

The kinematic viscosity and fluidity are calculated from the measured dynamic viscosity and density of the three samples.

Graphs are constructed using the Grafer software, and the mode of the functional dependence and the coefficient of determination are calculated. The results are presented in Table II to VIII and in Figures 1 to 4. 
TABLE I. MEASURED ENERGETIC VALUES OF THREE PLANTOHYD SAMPLES

\begin{tabular}{|c|c|c|c|}
\hline Type & $m(g)$ & $H(J / g)$ & $\bar{H}(M J / k g)$ \\
\hline \multirow{2}{*}{ Plantohyd $15 \mathrm{~S}$} & 0.2363 & 37511 & \multirow{2}{*}{37.428} \\
\hline & 0.5100 & 37345 & \\
\hline \multirow{2}{*}{ Plantohyd 46S } & 0.2667 & 39521 & \multirow{2}{*}{39.483} \\
\hline & 0.5554 & 39457 & \\
\hline \multirow{2}{*}{ Plantohyd $40 \mathrm{~N}$} & 0.3334 & 39466 & \multirow{2}{*}{39.417} \\
\hline & 0.5963 & 39378 & \\
\hline
\end{tabular}

TABLE II. MEASURED VALUES OF $\eta, v, \varphi, \rho$ - PLANTOHYD $15 \mathrm{~S}$

\begin{tabular}{|c|c|c|c|c|}
\hline$t\left({ }^{\circ} \mathrm{C}\right)$ & $\rho$ \\
$\left(\mathrm{kg} / \mathrm{m}^{3}\right)$ & $(\mathrm{mPa} \cdot s)$ & $\begin{array}{c}\nu \\
\left(\mathrm{m}^{2} / \mathrm{s} \cdot 10^{-6}\right)\end{array}$ & $\begin{array}{c}\varphi \\
\left(\mathrm{Pa}^{-1} \cdot \mathrm{s}^{-1}\right)\end{array}$ \\
\hline-10 & 939.974 & 79.3 & 84.41 & 12.61 \\
\hline-5 & 937.897 & 75.8 & 80.87 & 13.19 \\
\hline 0 & 934.776 & 62.4 & 66.77 & 16.03 \\
\hline 5 & 931.656 & 57.1 & 61.26 & 17.51 \\
\hline 10 & 928.537 & 51.2 & 55.17 & 19.53 \\
\hline 20 & 922.298 & 45.9 & 49.79 & 21.79 \\
\hline 30 & 913.980 & 35.5 & 38.84 & 28.17 \\
\hline 40 & 908.781 & 24.0 & 26.41 & 41.67 \\
\hline 50 & 902.542 & 21.7 & 23.99 & 46.08 \\
\hline
\end{tabular}

TABLE III. MEASURED VALUES OF $\eta, v, \varphi, \rho$ - PLANTOHYD $46 \mathrm{~S}$

\begin{tabular}{|c|c|c|c|c|}
\hline$t\left({ }^{\circ} C\right)$ & $\begin{array}{c}\rho \\
\left(\mathrm{kg} / \mathrm{m}^{3}\right)\end{array}$ & $\begin{array}{c}\eta \\
(m P a \cdot s)\end{array}$ & $\begin{array}{c}v \\
\left(m^{2} / s \cdot 10^{-6}\right)\end{array}$ & $\begin{array}{c}\varphi \\
\left(P a^{-1} \cdot s^{-1}\right)\end{array}$ \\
\hline-10 & 927.497 & 216.4 & 233.30 & 4.62 \\
\hline-5 & 926.457 & 166.3 & 179.50 & 6.01 \\
\hline 0 & 925.417 & 122.5 & 132.37 & 8.16 \\
\hline 5 & 924.378 & 102.2 & 110.55 & 9.78 \\
\hline 10 & 922.298 & 84.6 & 91.70 & 11.81 \\
\hline 20 & 913.980 & 61.2 & 66.95 & 16.34 \\
\hline 30 & 907.741 & 50.9 & 56.05 & 19.65 \\
\hline 40 & 900.462 & 43.2 & 48.01 & 23.15 \\
\hline 50 & 896.303 & 37.6 & 41.95 & 26.59 \\
\hline
\end{tabular}

TABLE IV. MEASURED VALUES OF $\eta, v, \varphi, \rho-$ PLANTOHYD $40 \mathrm{~N}$

\begin{tabular}{|c|c|c|c|c|}
\hline$t\left({ }^{\circ} \mathrm{C}\right)$ & $\rho$ & $\begin{array}{c}\nu \\
(\mathrm{mPa} \cdot \mathrm{s})\end{array}$ & $\begin{array}{c}\varphi \\
\left(\mathrm{m}^{2} / \mathrm{s} \cdot 10^{-6}\right)\end{array}$ & $\left(\mathrm{Pa}^{-1} \cdot \mathrm{s}^{-1}\right)$ \\
\hline-10 & 934.776 & 233.7 & 239.30 & 4.28 \\
\hline-5 & 937.696 & 174.7 & 186.30 & 5.37 \\
\hline 0 & 930.616 & 132.3 & 142.16 & 7.56 \\
\hline 5 & 926.457 & 93.7 & 10109 & 10.67 \\
\hline 10 & 922.298 & 69.8 & 75.73 & 14.33 \\
\hline 20 & 918.139 & 54.9 & 59.79 & 18.21 \\
\hline 30 & 906.701 & 47.5 & 52.39 & 21.05 \\
\hline 40 & 904.621 & 39.3 & 43.45 & 25.45 \\
\hline 50 & 897.343 & 36.2 & 40.38 & 27.62 \\
\hline
\end{tabular}

TABLE V. RESULTS FOR FUNCTIONAL DEPENDENCE AND COEFFICIENT OF DETERMINATION FOR DENSITY $\rho=f(t)$

\begin{tabular}{|c|c|c|}
\hline Type & Equation & Association coefficient \\
\hline $15 \mathrm{~S}$ & $\mathrm{Y}=-0.642 \mathrm{x}+934.4$ & $\mathrm{R}^{2}=0.997$ \\
\hline $46 \mathrm{~S}$ & $\mathrm{Y}=-0.566 \mathrm{x}+924.8$ & $\mathrm{R}^{2}=0.974$ \\
\hline $40 \mathrm{~N}$ & $\mathrm{Y}=-0.675 \mathrm{x}+930.3$ & $\mathrm{R}^{2}=0.976$ \\
\hline
\end{tabular}

TABLE VI. RESULTS FOR FUNCTIONAL DEPENDENCE AND COEFFICIENT OF DETERMINATION FOR DYNAMIC VISCOSITY $\eta=f(t)$

\begin{tabular}{|c|c|c|}
\hline Type & Equation & Association coefficient \\
\hline $15 \mathrm{~S}$ & $\begin{array}{c}Y=-0.000 x^{3}+0.015 x^{2}-1.369 x+ \\
64.87\end{array}$ & $\mathrm{R}^{2}=0.986$ \\
\hline $46 \mathrm{~S}$ & $\begin{array}{c}Y=-0.001 x^{3}+0.181 x^{2}-6.447 x+ \\
129.4\end{array}$ & $\mathrm{R}^{2}=0.997$ \\
\hline $40 \mathrm{~N}$ & $\begin{array}{c}Y=-0.002 x^{3}+0.236 x^{2}-7.761 x+ \\
129.8\end{array}$ & $\mathrm{R}^{2}=0.997$ \\
\hline
\end{tabular}

TABLE VII. RESULTS FOR FUNCTIONAL DEPENDENCE AND COEFFICIENT OF DETERMINATION FOR KINEMATIC VISCOSITY $v=f(t)$

\begin{tabular}{|c|c|c|}
\hline Type & Equation & $\begin{array}{l}\text { Association } \\
\text { coefficient }\end{array}$ \\
\hline $15 \mathrm{~S}$ & $\begin{array}{c}\mathrm{Y}=-1 \mathrm{E}-10 \mathrm{x}^{3}+2 \mathrm{E}-08 \mathrm{x}^{2}-1 \mathrm{E}-06 \mathrm{x}+ \\
7 \mathrm{E}-05\end{array}$ & $\mathrm{R}^{2}=0.985$ \\
\hline $46 \mathrm{~S}$ & $\begin{array}{c}\mathrm{Y}=-2 \mathrm{E}-09 \mathrm{x}^{3}+2 \mathrm{E}-07 \mathrm{x}^{2}-7 \mathrm{E}-06 \mathrm{x}+ \\
0.000\end{array}$ & $\mathrm{R}^{2}=0.997$ \\
\hline $40 \mathrm{~N}$ & $\begin{array}{c}Y=-2 E-09 x^{3}+2 E-07 x^{2}-8 E-06 x+ \\
0.000\end{array}$ & $\mathrm{R}^{2}=0.997$ \\
\hline
\end{tabular}

TABLE VIII. RESULTS FOR FUNCTIONAL DEPENDENCE AND COEFFICIENT OF DETERMINATION FOR FLUIDITY $\varphi=f(t)$

\begin{tabular}{|c|c|c|}
\hline Type & Equation & Association coefficient \\
\hline $15 \mathrm{~S}$ & $\mathrm{Y}=15.35 \mathrm{e}^{0.022 \mathrm{x}}$ & $\mathrm{R}^{2}=0.983$ \\
\hline $46 \mathrm{~S}$ & $\mathrm{Y}=0.374 \mathrm{x}+8.184$ & $\mathrm{R}^{2}=0.998$ \\
\hline $40 \mathrm{~N}$ & $\mathrm{Y}=0.411 \mathrm{x}+8.547$ & $\mathrm{R}^{2}=0.984$ \\
\hline
\end{tabular}

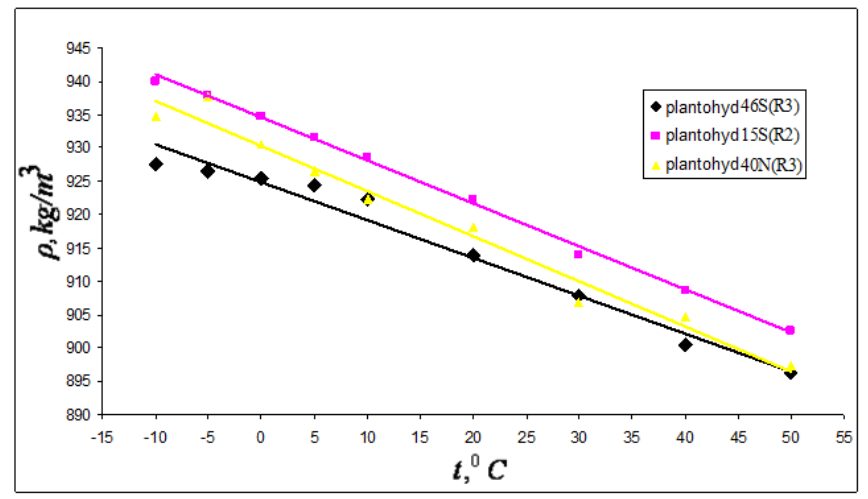

Fig. 1. Dependence of density on temperature.

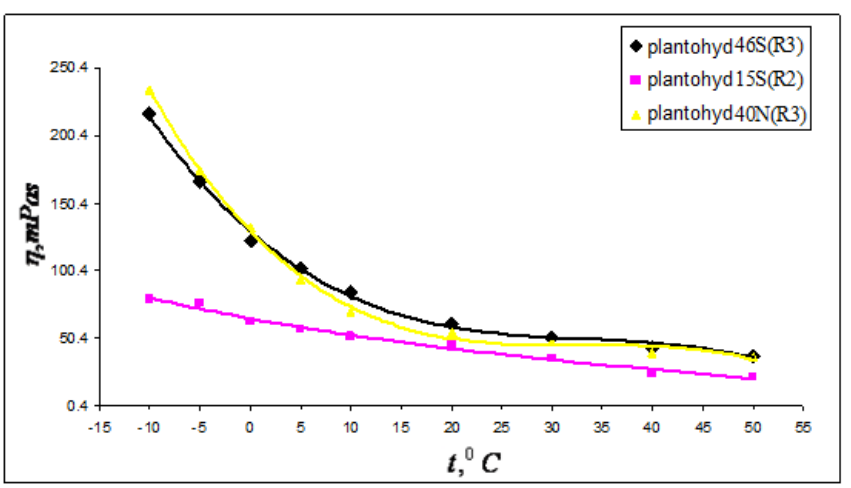

Fig. 2. Dependence of dynamic viscosity on temperature. 


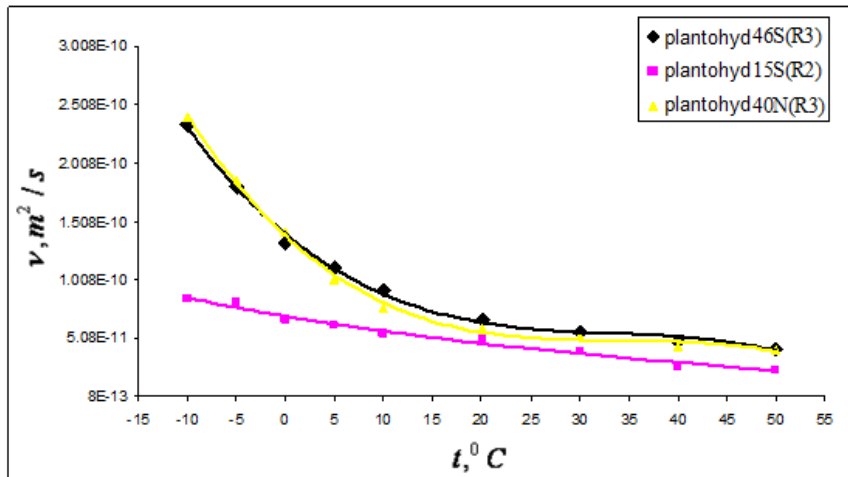

Fig. 3. Dependence of kinematic viscosity on temperature.

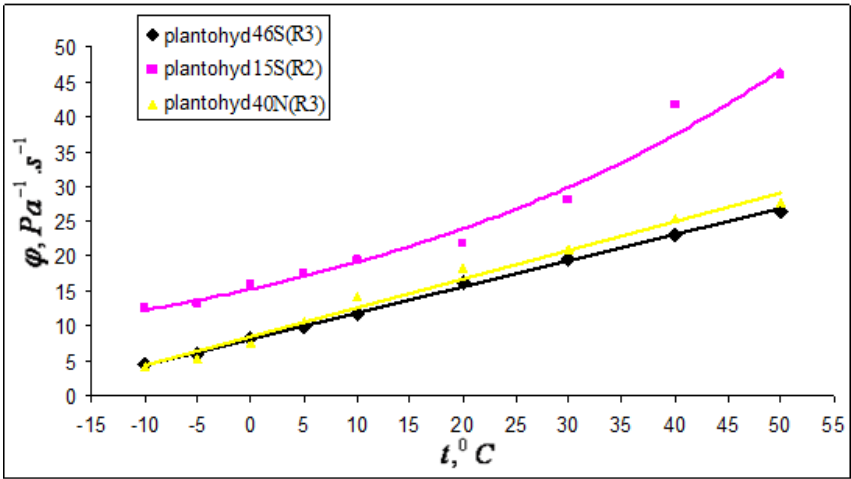

Fig. 4. Dependence of fluidity on temperature.

\section{A. Analysis of results}

The results for the energetic values show that they are very close for both Plantohyd $46 \mathrm{~S}$ and $40 \mathrm{~N}$ and lower for $15 \mathrm{~S}$.

Constructed graphs of the dependence of density on temperature show a linear decreasing function for all three samples.

Dependence is:

$$
\rho=A-B(t)
$$

where $A$ and $B$ are constants that depend on the type of substance.

The values of densities fall in the following ranges:

- Plantohyd 15S: from $939.97 \mathrm{~kg} / \mathrm{m}^{3}$ at $-10^{0} \mathrm{C}$ to $902.54 \mathrm{~kg} / \mathrm{m}^{3}$ at $+50^{\circ} \mathrm{C}$.

- Plantohyd 46S: from $927.50 \mathrm{~kg} / \mathrm{m}^{3}$ at $-10^{0} \mathrm{C}$ to $896.30 \mathrm{~kg} / \mathrm{m}^{3}$ at $+50^{\circ} \mathrm{C}$.

- Plantohyd $40 \mathrm{~N}$ : from $934.78 \mathrm{~kg} / \mathrm{m}^{3}$ at $-10^{0} \mathrm{C}$ to $897.34 \mathrm{~kg} / \mathrm{m}^{3}$ at $+50^{0} \mathrm{C}$.

It can be seen from the graphs that Plantohyd $46 \mathrm{~S}$ and $40 \mathrm{~N}$ have slightly different densities after $+400 \mathrm{C}$, and that Plantohyd $15 \mathrm{~S}$ has the highest density values.

Our results for Plantohyd densities are comparable to results given in reference books (for Plantohyd 46S: 921 $\mathrm{kg} / \mathrm{m}^{3}$, for Plantohyd $40 \mathrm{~N}: 922 \mathrm{~kg} / \mathrm{m}^{3}$, data for Plantohyd $15 \mathrm{~S}$ were not found, but for Plantohyd 32S density is $921 \mathrm{~kg} / \mathrm{m}^{3}$ ).
The results for $\eta$ show that dependence on $t$ is not exponential and not linear. It rather follows a cubic decrease.

Dependence is:

$$
\eta=C-D(t)+I(t)^{2}-F(t)^{3}
$$

where $C, D, F$ and $I$ are constants that depend on the type of substance.

The values of dynamic viscosity for Plantohyd $46 \mathrm{~S}$ and $40 \mathrm{~N}$ are close:

- $\quad$ Plantohyd 46S: $216.4 \mathrm{mPa} \cdot \mathrm{s}$ at $-10^{0} \mathrm{C}$ to $37.6 \mathrm{mPa} \cdot \mathrm{s}$ at $+50^{\circ} \mathrm{C}$.

- $\quad$ Plantohyd $40 \mathrm{~N}: 233.7 \mathrm{mPa} \cdot \mathrm{s}$ at $-10^{0} \mathrm{C}$ to $36.2 \mathrm{mPa} \cdot \mathrm{s}$ at $+50^{\circ} \mathrm{C}$.

Significantly, lower values of dynamic viscosity are for Plantohyd 15S: $79.3 \mathrm{mPa} \cdot \mathrm{s}$ at $-10^{\circ}$ to $21.7 \mathrm{mPa} \cdot \mathrm{s}$ at $+50^{\circ}$ C.

Similar results can be seen for the dependence of kinematic viscosity on temperature. Decreasing dependence is cubic.

Dependence is

$$
v=G-H(t)+M(t)^{2}-N(t)^{3}
$$

$G, H, M$ and $N$ are constants that depend on the type of substance.

Values for $46 \mathrm{~S}$ and $40 \mathrm{~N}$ are relatively close, and those for $15 \mathrm{~S}$ are smaller. The results are as follows:

- $\quad$ Plantohyd 46S: $233.3 \cdot 10^{-6} \mathrm{~m}^{2} / \mathrm{s}$ at $-10^{0} \mathrm{C}$ and $41.9 \cdot 10^{-}$ ${ }^{6} \mathrm{~m}^{2} / \mathrm{s}$ at $+50{ }^{0} \mathrm{C}$.

- Plantohyd $40 \mathrm{~N}: 239.3 \cdot 10^{-6} \mathrm{~m}^{2} / \mathrm{s}$ at $-10^{0} \mathrm{C}$ and $40.4 \cdot 10^{-6} \mathrm{~m}^{2} / \mathrm{s}$ at $+50^{\circ} \mathrm{C}$.

- Plantohyd 15S: $84.4 \cdot 10^{-6} \mathrm{~m}^{2} / \mathrm{s}$ at $-10^{0} \mathrm{C}$ and $23.9 \cdot 10^{-6}$ $\mathrm{m}^{2} / \mathrm{s}$ at $+50^{\circ} \mathrm{C}$.

Comparison of the results can be made with the given values of kinematic viscosity characteristics of those lubricants at $40^{\circ} \mathrm{C}$.

- Plantohyd $46 \mathrm{~S}: 48.8 \cdot 10^{-6} \mathrm{~m}^{2} / \mathrm{s}$ - our calculatted value is $48.01 \cdot 10^{-6} \mathrm{~m}^{2} / \mathrm{s}$.

- Plantohyd $40 \mathrm{~N}: 42 \cdot 10^{-6} \mathrm{~m}^{2} / \mathrm{s}$ - our calculatted value is $43.4 \cdot 10^{-6} \mathrm{~m}^{2} / \mathrm{s}$.

- Plantohyd 15S: no evidence for kinematic viscosity.

The dependence of fluidity on temperature is a linearly increasing function of Plantohyd 46S and Plantohyd 40N.

Dependence is:

$$
\varphi=K+L(t)
$$

Dependence for Plantohyd 15S is:

$$
\varphi=K \exp L(t)
$$

$K$ and $L$ are constants that depend on the type of substance.

These functions are not differing significantly at temperatures from $-10^{\circ} \mathrm{C}$ to $+10^{0} \mathrm{C}$. The obtained values for fluidity are: 
- Plantohyd 46S: from $4.62 \mathrm{~Pa}^{-1} \cdot \mathrm{s}^{-1}$ at $-10^{0} \mathrm{C}$ to 26.59 $\mathrm{Pa}^{-1} \cdot \mathrm{s}^{-1}$ at $+50^{0} \mathrm{C}$.

- Plantohyd 40N: from $4.28 \mathrm{~Pa}^{-1} \cdot \mathrm{s}^{-1}$ at $-10^{0} \mathrm{C}$ to 27.62 $\mathrm{Pa}^{-1} \cdot \mathrm{s}^{-1}$ at $+50^{0} \mathrm{C}$.

The dependence of fluidity on temperature for Plantohyd $15 \mathrm{~S}$ is an exponentially increasing function.

The obtained values for fluidity are from $12.61 \mathrm{~Pa}^{-1} \cdot \mathrm{s}^{-1}$ at $-10^{0} \mathrm{C}$ to $46.08 \mathrm{~Pa}^{-1} \cdot \mathrm{s}^{-1}$ at $+50^{0} \mathrm{C}$.

\section{CONCLUSION}

Lubricants are classified by their two main characteristics: viscosity and operational level - the kinematic viscosity. The physical interpretation of the results of energy values and the dependence of rheological properties on temperature can be used to assess the quality of lubricants. Using bio lubricants helps to lubricate the engine, providing longer engine and segment life. Suitability for use of a bio lubricant is estimated with the help of certain criteria. As one of the roles of fuel and lubrication is its function, the change of its viscosity and its density are indicative of a change in quality. The viscosity values show the ability to withstand and protect against wear and corrosion. The results presented in this paper can be useful for manufacturers of similar synthetic oils and could be used by the automotive and mechanical engineering industry, which uses similar lubricants. Further, the data obtained can be used in technological processes as well as for studying the physical properties of bio lubricants which would allow the development of new technologies using bioenergetics conversion and use of bio lubricants with better performance.

\section{REFERENCES}

[1] Fuchs Europe Schmierstoffe GMBH, "PLANTOHYD S: Environmentally-friendly, synthetic ester-based hydraulic and lubricating fluid (product information)", PI 4-1274, PM 4 /03.08, 2008

[2] J. Krempasky, Fyzika, Alfa, 1982

[3] V. Vozarova, "Study of processes and properties of materials by method of thermal analysis", Research and Teaching of Physics in the Context of University Education International Conference, Nitra, Slovakia, pp. 141-144, June, 2007

[4] J. Moran, N. Shapiro, Fundamentals of engineering thermodynamics, John Wiley \& Sons, 1991

[5] P. Haines, Thermal methods of analysis: principles, appplications and problems, Blackie Akademic and Proffessional, 1995

[6] A. Blazek, Termicka analiza, STNL, 1972

[7] M. Valach, L. Hires, "Examination of viscosity and specific heat of combustion of biofuels", Physics-Research-Applications-Education International Conference, Nitra, Slovakia, pp.138-140, October, 2011

[8] M. Bozikova, P. Hlavac, Selected physical properties of agricultural and food products, Slovak University of Agriculture, Nitra, Slovakia, 2010

[9] P. Hlavac, "The rheologic properties of plum jam", PTEP Journal of Processing and Energy in Agriculture, Vol. 11, No. 3, pp. 106-108, 2007 